\title{
Quantative trait loci of seed traits for soybean in multiple environments
}

\author{
J.Y. Che ${ }^{1,3, *}$, J.J. Ding ${ }^{4, *}$, C.Y. Liu ${ }^{1}$, D.W. Xin ${ }^{1}$, H.W. Jiang ${ }^{1,2}$, \\ G.H. $\mathrm{Hu}^{2}$ and Q.S. Chen ${ }^{1}$
}

${ }^{1}$ Key Laboratory of Soybean Biology, Soybean Research Institute, Ministry of Education, Northeast Agricultural University, Harbin, Heilongjiang, China

${ }^{2}$ Land Reclamation Research and Breeding Centre of Heilongjiang, Harbin, Heilongjiang, China

${ }^{3}$ Keshan Sub-Academy of Heilongjiang, Academy of Agricultural Sciences, Keshan, Heilongjiang, China

${ }^{4}$ Jiamusi Sub-Academy of Heilongjiang, Academy of Agricultural Sciences, Jiamusi, Heilongjiang, China

*These authors contributed equally to this study.

Corresponding authors: Q.S. Chen / G.H. Hu

E-mail: qshchen@126.com / hugh757@vip.163.com

Genet. Mol. Res. 13 (2): 4000-4012 (2014)

Received August 7, 2013

Accepted December 10, 2013

Published May 23, 2014

DOI http://dx.doi.org/10.4238/2014.May.23.11

ABSTRACT. Seed length and seed width are an important factor to the soybean yield. So the quantitative trait loci (QTL) location for seed length and seed width could assistant the breeding of soybean. In this study, the QTL underlying seed length and seed width were studied. A recombinant inbred line population of soybeans derived from a cross between the American semi-draft cultivars Charleston and Dongnong 594 were used in 7 environments. The quantitative trait loci underlying seed length, seed width, and seed length/seed width were analyzed by the method of composite interval mapping. Then, the epistatic effects and the QTL-environment (QE) interaction effects were also analyzed. Some valuable QTL sites found had great 
effect to the seed trait. Results showed that 7 QTLs underlying seed length were identified mainly on linkage groups D1a, C2, B1, A1, G, and A2. For the seed width, 7 QTLs were identified on linkage groups D1a and O. Two QTLs of seed length/seed width were identified on linkage groups D1b and C2. No QE interaction was found for QTLs of seed length and seed width in 7 environments. QTLs of seed length/seed width on linkage groups A1 and I had a QE interaction in 7 environments. Seven pairs of QTLs were identified that affected additive $\mathrm{x}$ additive epistatic effect of seed length, seed width, and seed length/seed width, which occurred among 8 linkage groups. These results supply a good foundation for molecular assistant breeding for soybean seed trait.

Key words: Soybean; Seed length; Seed width; Quantitative trait locus; Quantitative trait locus-environment interaction

\section{INTRODUCTION}

Soybean seed traits directly impart the composition of yield. Identifying the quantitative trait loci (QTLs) underlying seed traits is very useful for marker-assisted breeding. Seed size, seed weight, pods per plant, and number of seeds per plant are the main factors that determine soybean yield (Jin et al., 2010; Yesudas et al., 2013). By modifying genetic linkage maps, some QTLs of seed traits were identified, such as pod number, seed size, seed hardness, and seed weight (Keim et al., 1990; Lu et al., 1997; Tasma et al., 2001; Zhang et al., 2010). Significant progress has been made in understanding the regulation of seed formation through molecular and genetic studies of rice (Kitagawa et al., 2010). Now, more QTLs underlying seed traits have been identified in rice and maize than in other crops; especially in rice, a huge number of QTLs and genes of seed length and seed width were found (McKenzie and Rutger, 1983; Song et al., 2007). In addition, several functional genes involved in grain length and weight in rice were identified (Heang and Sassa, 2012; Ishimaru et al., 2013). Especially for maize, some seed trait genes were identified based on meta-analysis of yield-related QTLs from public resources (Wang et al., 2013).

Many studies showed that seed width was controlled by multiple genes. Nineteen QTLs underlying seed length and 14 QTLs underlying seed width were identified using 3 sets of recombinant lines: Minsoy x Archer, Minsoy x Noirl, and Noirl x Archer (Salas et al., 2006). Genetic analysis of the soybean seed trait revealed that seed length and seed width of the hybrid $F_{1}$ of a reciprocal cross were significantly different, suggesting the existence of a maternal inheritable effect. The seed length trait was jointly controlled by a pair of additive, dominant major genes and additive, dominant, and epistatic genes; seed width was controlled by multiple genes.

Five main effect QTL were found in three population [F(2:3), F(2:4) and $\mathrm{F}(2: 5)]$, had higher heritability, greater than $20 \%$, which population derived from the direct and reciprocal crosses of Lishuizhongzihuang with Nannong 493-1 (Xu et al., 2011). By the empirical Bayes algorithm, a 307-bp allele of QTL linked to satt453 was found via 257 soybean cultivars obtained by stratified random sampling from six geographic ecotypes in China (Niu et 
al., 2013). The Harosoy and Clark cultivars were used as donator parents to construct two primary backcross introgression line, Hongfeng 11 was used as recurrent parent, and QTLs for large pods and seeds and related traits were located. Thirty-seven related QTLs were identified for 13 pod and seed traits, which were distributed on 18 linkage groups in 2 sets of introgression line groups. QTLs for seed length were identified on chromosomes F, J, and M, respectively. A seed width QTL was identified on chromosome C1 (Li et al., 2008). The Jindou $23 \times$ Huibuzhi line was used to construct 474 family lines of $F_{13}$ recombinant inbred line groups to use as a mapping population in soybean. A genetic map with 231 simple sequence repeat markers was constructed. Seed length, seed width, seed thickness, length/ width, length/thickness, and width/thickness were studied in soybean. The analysis showed that 7 QTLs for seed length were located on chromosomes D1a, D2, and J_2, and 3 QTLs for seed width were located on chromosomes B1 and O (Liang et al., 2008).

In this study, QTLs underlying seed length, seed width, and seed length/seed width were identified for the first time in 7 different environments from 2006 to 2010 . Some stable QTLs underlying seed length and seed width were found, and the QTL-environment (QE) interactions were also analyzed. Our results are very useful for gene mining and molecular breeding in soybean, which has a complex genetic background.

\section{MATERIAL AND METHODS}

\section{Experimental materials}

The $\mathrm{F}_{2-14}$ generations of a recombinant inbred line population including 147 lines derived from a cross between the American semi-draft cultivars Charleston and China variety Dongnong 594 were used from 2006 to 2010. The recombinant inbred lines were grown together with the parents at Harbin $\left(45^{\circ} 43^{\prime} \mathrm{N}, 126^{\circ} 45^{\prime} \mathrm{E}\right.$, fine-mesic chernozen soil) and Hongxinglong $\left(46^{\circ} 43^{\prime} \mathrm{N}, 131^{\circ} 34^{\prime} \mathrm{E}\right.$, fine-mesic chernozen soil) during 2006-2010. Seeds were planted in rows that were $5 \mathrm{~m}$ long and spaced $0.65 \mathrm{~m}$ apart and with a space of $5 \mathrm{~cm}$ between plants. Two replicates were used with a randomized complete block design from 2006 to 2007, and 3 replicates were used with a randomized complete block design from 2008 to 2010 . Five plants of each line were randomly selected in each row as seed and pod trait donors that were later used to analyze and record the data from the usual methods for soybean (Sun et al., 2012).

\section{Statistics and analysis}

The length and width of 10 pods were measured per plant, and the average value was used as the phenotypic value of each line. A genetic map was constructed by our lab; this genetic map had 20 linkage groups. The total length of the genetic map was $1913.5 \mathrm{cM}$, the average distance between markers was $11.89 \mathrm{cM}$, and the length of each linkage group ranged from 0.4 to $309.5 \mathrm{cM}$ (Sun et al., 2012). QTL testing for seed length, seed width, and seed length/seed width was performed using composite interval method (CIM) of QTLCart 2.5 software. The permutation test method was used to estimate the logarithm of odds (LOD) significant threshold value, and samples were repeated 1000 times. The QTLNetwork_v2.1 software was used to analyze QTL epistatic effects and QE interaction effects. 


\section{RESULTS}

\section{Phenotypic variation of 2 parents}

From Table 1, it could be seen that the phenotypes of the 2 parents varied by the change in different locations from 2006 to 2010. The phenotype value of seed length/seed width of Dongnong 594 was greater than that of Charleston. The mid-parent value of seed length and seed width was the smallest in 2008.

\begin{tabular}{|c|c|c|c|c|c|c|c|}
\hline \multirow[t]{2}{*}{ Year } & \multirow[t]{2}{*}{ Parent } & \multicolumn{2}{|c|}{ Seed length (mm) } & \multicolumn{2}{|c|}{ Seed width (mm) } & \multicolumn{2}{|c|}{ Seed length/seed width } \\
\hline & & Mean & Mid-parent value & Mean & Mid-parent value & Mean & Mid-parent value \\
\hline \multirow[t]{2}{*}{2006 (A) } & Charleston & 7.440 & \multirow[t]{2}{*}{7.29} & 6.880 & \multirow[t]{2}{*}{6.62} & 1.081 & \multirow[t]{2}{*}{1.102} \\
\hline & Dongnong 594 & 7.140 & & 6.360 & & 1.123 & \\
\hline \multirow[t]{2}{*}{2007 (A) } & Charleston & 7.240 & \multirow[t]{2}{*}{7.53} & 6.580 & \multirow[t]{2}{*}{6.60} & 1.100 & \multirow[t]{2}{*}{1.140} \\
\hline & Dongnong 594 & 7.820 & & 6.620 & & 1.181 & \\
\hline \multirow[t]{2}{*}{2008 (A) } & Charleston & 6.433 & \multirow[t]{2}{*}{6.752} & 5.580 & 5.252 & 1.153 & \multirow[t]{2}{*}{1.294} \\
\hline & Dongnong 594 & 7.070 & & 4.923 & & 1.436 & \\
\hline \multirow[t]{2}{*}{2009 (A) } & Charleston & 7.247 & \multirow[t]{2}{*}{7.204} & 6.567 & 6.308 & 1.104 & \multirow[t]{2}{*}{1.144} \\
\hline & Dongnong 594 & 7.160 & & 6.050 & & 1.183 & \\
\hline \multirow[t]{2}{*}{2009 (B) } & Charleston & 7.147 & \multirow[t]{2}{*}{6.876} & 6.433 & 6.020 & 1.111 & \multirow[t]{2}{*}{1.144} \\
\hline & Dongnong 594 & 6.605 & & 5.608 & & 1.178 & \\
\hline \multirow[t]{2}{*}{2010 (A) } & Charleston & 7.940 & \multirow[t]{2}{*}{7.816} & 7.153 & 6.76 & 1.110 & \multirow[t]{2}{*}{1.159} \\
\hline & Dongnong 594 & 7.693 & & 6.367 & & 1.208 & \\
\hline \multirow[t]{2}{*}{2010 (B) } & Charleston & 7.567 & \multirow[t]{2}{*}{7.574} & 6.573 & 6.241 & 1.151 & \multirow[t]{2}{*}{1.217} \\
\hline & Dongnong 594 & 7.582 & & 5.909 & & 1.283 & \\
\hline
\end{tabular}

\section{Phenotypic variance of the recombinant inbred line groups}

The phenotype data of seed length, seed width, and seed length/seed width showed a normal distribution in the recombinant inbred line. However, the average values of these 3 traits were similar to the parents. Therefore, these 3 traits were quantitative traits that were dominated by multiple genes. In some years, the standard deviation and kurtosis of seed length/seed width was greater, indicating that different environmental conditions had a huge effect on the phenotype of seed length/seed width. The skewness of seed length, seed width, and seed length/seed width was relatively small; individual traits had partial parental separation. From the phenotypic data of frequency distribution, each trait showed an approximately normal continuous distribution, which was suitable for QTL analysis (Table 2, Figure 1).

\section{QTL mapping}

QTL testing of seed length, seed width, and seed length/seed width was performed using the CIM method in the QTLCart 2.5 software. The LOD significant threshold values of traits were estimated by a permutation test using samples that were repeated 1000 times.

The data of seed length, seed width, and seed length/seed width were analyzed during 2006 to 2010. Seven QTLs underlying seed length were identified on linkage groups 
$\mathrm{D} 1 \mathrm{a}, \mathrm{C} 2, \mathrm{~B} 1, \mathrm{~A} 1, \mathrm{G}$, and $\mathrm{A} 2$. The contribution rates ranged from 0 to $0.16 \%$, the additive effect was -0.23 to 0.20 , and the LOD values ranged from 3 to 6.03 (Table 3, Figure 2). Six QTLs underlying seed width were identified on linkage groups D1a and O. The contribution rates ranged from 0 to $0.19 \%$, the variation that was explained by the trait was $0.76 \%$, and the LOD values ranged from 3.13 to 5.98 . Two QTLs underlying seed length/seed width were identified on linkage group Dla in 2006 (A) and 2009 (B). The contribution rates ranged from 0.08 to $0.11 \%$, the variation that was explained by the trait was $0.19 \%$, the LOD values ranged from 3.11 to 3.38 , and additive effects were relatively small and from the female parent.

\begin{tabular}{|c|c|c|c|c|c|c|c|}
\hline Year & Trait & Max. $(\%)$ & Min. $(\%)$ & Mean (\%) & SD & Kurtosis & Skewness \\
\hline \multirow[t]{3}{*}{2006 (A) } & Seed length & 8.29 & 6.565 & 7.182 & 0.30 & 1.160 & 0.60 \\
\hline & Seed width & 7.12 & 6.01 & 6.563 & 0.23 & -0.020 & -0.16 \\
\hline & Seed length/seed width & 1.22 & 1.033 & 1.09 & 9.45 & 5.370 & 1.67 \\
\hline \multirow{3}{*}{2007 (A) } & Seed length & 8.47 & 7.313 & 6.51 & 0.34 & 1.420 & 0.81 \\
\hline & Seed width & 7.26 & 6.12 & 6.585 & 0.23 & 0.210 & 0.51 \\
\hline & Seed length/seed width & 1.209 & 1.048 & 1.11 & 0.03 & -0.030 & 0.43 \\
\hline \multirow{3}{*}{2008 (A) } & Seed length & 9.02 & 5.528 & 6.829 & 0.44 & 4.450 & 1.25 \\
\hline & Seed width & 6.38 & 4.367 & 5.686 & 0.27 & 3.320 & -0.73 \\
\hline & Seed length/seed width & 1.531 & 1.035 & 1.201 & 0.06 & 7.150 & 1.93 \\
\hline \multirow[t]{3}{*}{2009 (A) } & Seed length & 7.86 & 6.04 & 7.138 & 0.28 & 1.170 & -0.56 \\
\hline & Seed width & 6.88 & 5.24 & 6.311 & 0.26 & 1.410 & -0.58 \\
\hline & Seed length/seed width & 1.222 & 1.077 & 1.131 & 0.03 & -0.280 & 0.17 \\
\hline \multirow[t]{3}{*}{2009 (B) } & Seed length & 7.997 & 6.008 & 6.896 & 0.33 & 1.880 & 0.42 \\
\hline & Seed width & 6.607 & 5.095 & 5.978 & 0.25 & 1.410 & -0.51 \\
\hline & Seed length/seed width & 1.265 & 1.08 & 1.154 & 3.55 & -0.280 & 0.08 \\
\hline \multirow[t]{3}{*}{2010 (A) } & Seed length & 8.9 & 5.73 & 7.608 & 0.42 & 3.560 & -0.86 \\
\hline & Seed width & 7.267 & 4.88 & 6.582 & 0.36 & 3.280 & -0.98 \\
\hline & Seed length/seed width & 1.341 & 1.078 & 1.156 & 0.04 & 2.260 & 0.74 \\
\hline \multirow[t]{3}{*}{2010 (B) } & Seed length & 8.238 & 5.94 & 7.284 & 0.37 & 0.997 & -0.32 \\
\hline & Seed width & 6.781 & 5.04 & 6.024 & 0.33 & -0.100 & -0.03 \\
\hline & Seed length/seed width & 1.42 & 1.102 & 1.211 & 0.06 & 0.590 & 0.65 \\
\hline
\end{tabular}

\section{Analysis of QTL epistatic effects and QE interaction effects}

\section{Analysis of $Q E$ interaction effects}

Seed length/seed width QTLs had QE interaction effects. Two QTLs had environment interaction effects. These QTLs were located on linkage group A1 and I had additive effects values of 0.0155 and 0.0071 , respectively, which reached the 0.01 significance level (Table 4 ). The contribution rates of the additive effect were 6.25 and $3.04 \%$, the environment interaction contribution rates were 1.56 and $0.96 \%$, and the total contribution rates of the environmental effects were significantly smaller than the total contribution rates of the additive effects. The GM1-A1-17 QE interaction effects reached a significant level $(\mathrm{P}<0.05)$ in 2006 (A) and a significant level $(\mathrm{P}<0.01)$ in 2010 (B). The GM14-I-1 QTL did not have a significant QE interaction effect from 2006 to 2010 (Table 4). No QE interaction was found for the seed width and seed length characteristics. 

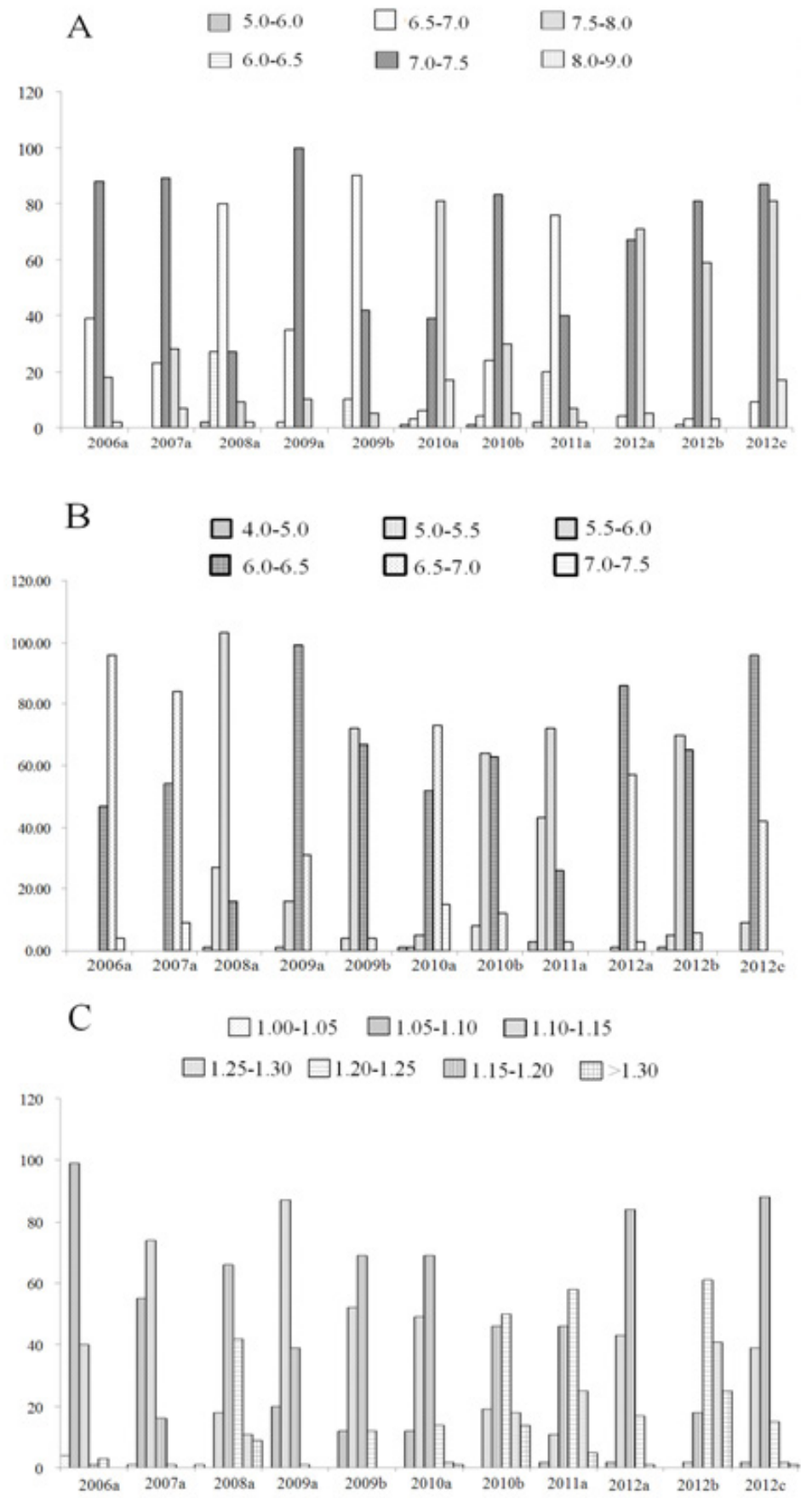

Figure 1. Frequency distribution of seed length, seed width, seed length/seed width of recombinant inbred line from 2006 to 2010. A. seed length, B. seed width, C. seed length/seed width. 
Table 3. Quantitative trait loci of seed length, seed width, seed length/seed width and related trait in population.

\begin{tabular}{|c|c|c|c|c|c|c|c|c|}
\hline Trait & Year & QTLs & Marker interval & Site & $\begin{array}{l}\text { Confidence } \\
\text { interval }\end{array}$ & LOD & $\begin{array}{l}\text { Contribution } \\
\text { rate }\end{array}$ & $\begin{array}{c}\text { Additive } \\
\text { effect }\end{array}$ \\
\hline \multirow[t]{10}{*}{ seed length } & 2006 (A) & GM7-D1a & satt383-satt267 & 224.4 & $224.0-228.9$ & 3.00 & 0.08 & 0.13 \\
\hline & 2007 (A) & GM6-C2 & satt334-satt460 & 109.6 & $98.9-115.6$ & 5.71 & 0.16 & -0.18 \\
\hline & $2008(\mathrm{~A})$ & GM3-B1 & satt197-satt229 & 61.7 & $59.0-66.0$ & 3.46 & 0.10 & -0.23 \\
\hline & 2009 (A) & GM1-A1 & satt242-satt270 & 191.6 & $184.9-196.9$ & 6.03 & 0.16 & -0.13 \\
\hline & & GM6-C2 & sat 092-satt202 & 128 & $123.7-132.1$ & 3.18 & 0.00 & 0.08 \\
\hline & 2009 (B) & GM7-D1a & satt226-satt175 & 56.4 & $52.9-62.3$ & 3.90 & 0.12 & 0.13 \\
\hline & & GM12-G & satt505-sat 094 & 13.7 & $2.7-16.7$ & 4.13 & 0.11 & -0.12 \\
\hline & 2010 (A) & GM1-A1 & satt242-satt270 & 191.6 & $174.8-196.2$ & 3.64 & 0.07 & -0.14 \\
\hline & & GM2-A2 & sat 036 -satt468 & 2.1 & $0.1-6.7$ & 5.83 & 0.15 & 0.17 \\
\hline & 2010 (B) & GM2-A2 & sat 036 -satt468 & 6.5 & $0.1-20.8$ & 3.06 & 0.09 & 0.12 \\
\hline \multirow[t]{7}{*}{ seed width } & 2006 (A) & GM7-D1a & satt383-satt515 & 231.1 & $224.0-232.9$ & 4.31 & 0.12 & 0.12 \\
\hline & 2008 (A) & GM7-D1a & sat 124 -satt220 & 126.3 & $120.5-133.0$ & 3.13 & 0.09 & -0.10 \\
\hline & 2009 (A) & GM7-D1a & sat 106-satt267 & 220.8 & $211.9-228.9$ & 4.45 & 0.12 & 0.12 \\
\hline & & GM20-O & satt173-satt581 & 29.4 & $23.7-31.0$ & 5.96 & 0.00 & 0.20 \\
\hline & 2009 (B) & GM20-O & satt173-satt581 & 29.4 & $25.8-31.0$ & 4.13 & 0.13 & 0.12 \\
\hline & 2010 (A) & GM20-O & satt173-satt581 & 29.4 & $24.3-31.0$ & 4.03 & 0.11 & 0.14 \\
\hline & 2010 (B) & GM20-O & satt173-satt581 & 29.4 & $24.1-31.0$ & 5.98 & 0.19 & 0.15 \\
\hline \multirow[t]{2}{*}{ seed length/seed width } & $2006(\mathrm{~A})$ & GM8-D1b & satt459-sat 135 & 39.3 & $28.3-52.8$ & 3.38 & 0.11 & 0.01 \\
\hline & 2009 (B) & GM6-C2 & satt460-satt202 & 127.7 & $123.3-133.4$ & 3.11 & 0.08 & 0.02 \\
\hline
\end{tabular}

$\mathrm{A}$ and $\mathrm{B}$, indicate that the experimental base of Heilongjiang Land Reclamation Research and Breeding Center and Hongxinglong agricultural experimental field, respectively.
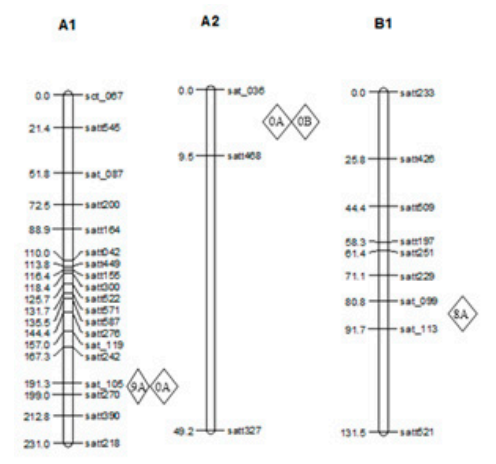

c2
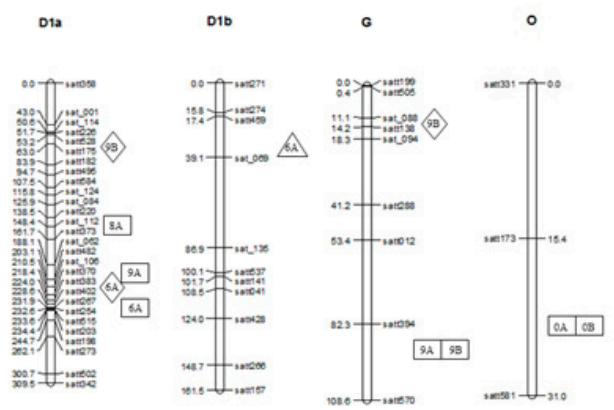

Figure 2. Loci distribution of seed length, seed width, and seed length/seed width of recombinant inbred line on linkage group. Diamond $=$ seed length; rectangle $=$ seed width; triangle $=$ seed length/seed width; 6, 7, 8, 9, and 0 indicate the years for 2006, 2007, 2008, 2009, and 2010, respectively. A and B indicate the experimental base of Heilongjiang Land Reclamation Research and Breeding Center and Hongxinglong agricultural experimental field, respectively. 


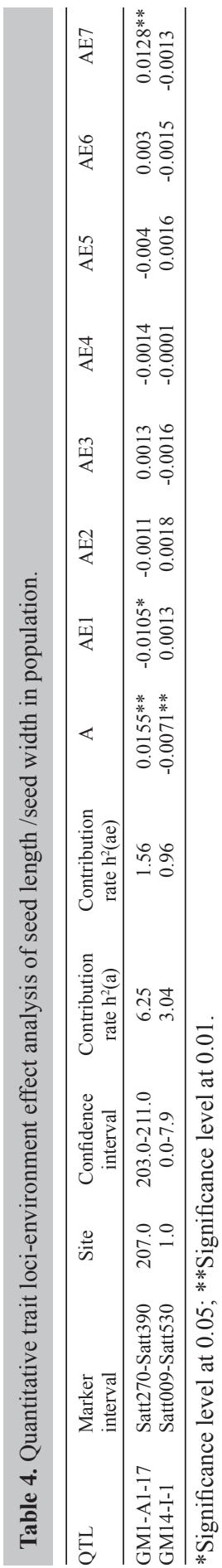




\section{Epistatic interaction effects of QTLs}

Seven pairs of QTLs that had additive $\mathrm{x}$ additive epistatic interaction effects were identified in 8 linkage groups (Figure 3, Table 5). One pair of seed length QTLs with additive $\mathrm{x}$ additive epistatic interaction effects occurred on the non-linkage interaction points GM15$\mathrm{J}-3$ and GM19-N-2. The additive effect value was 0.0537 , and it was significant at the 0.01 level. The additive $\mathrm{x}$ additive contribution rate was $1.77 \%$, the additive $\mathrm{x}$ additive environment contribution rate was $0.53 \%$, and the additive contribution rate was significantly greater than that of the additive environment contribution rate.

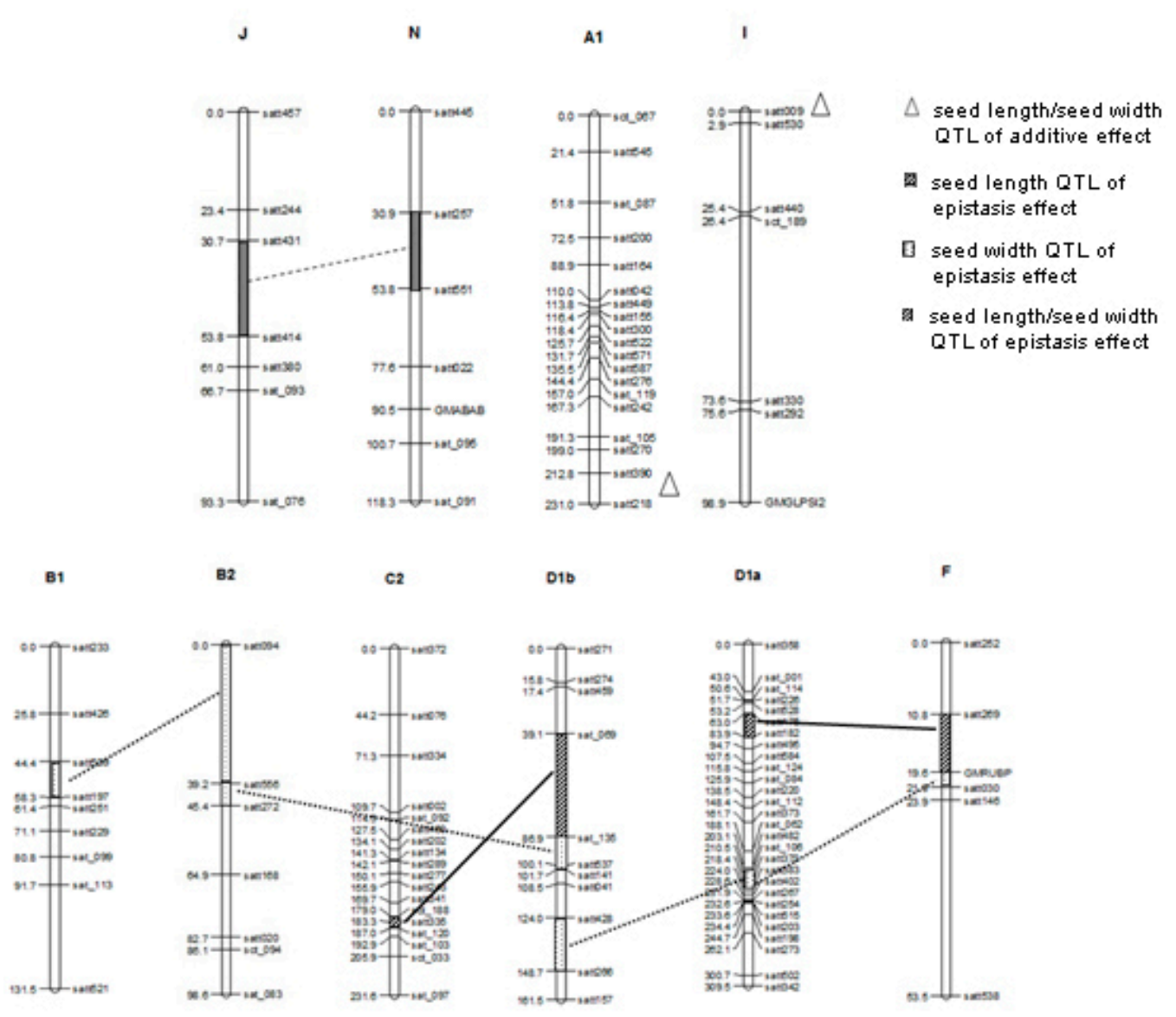

Figure 3. Distribution of the additive effect Quantitative trait loci (QTL) and epistatical effect QTL on linkage group. 


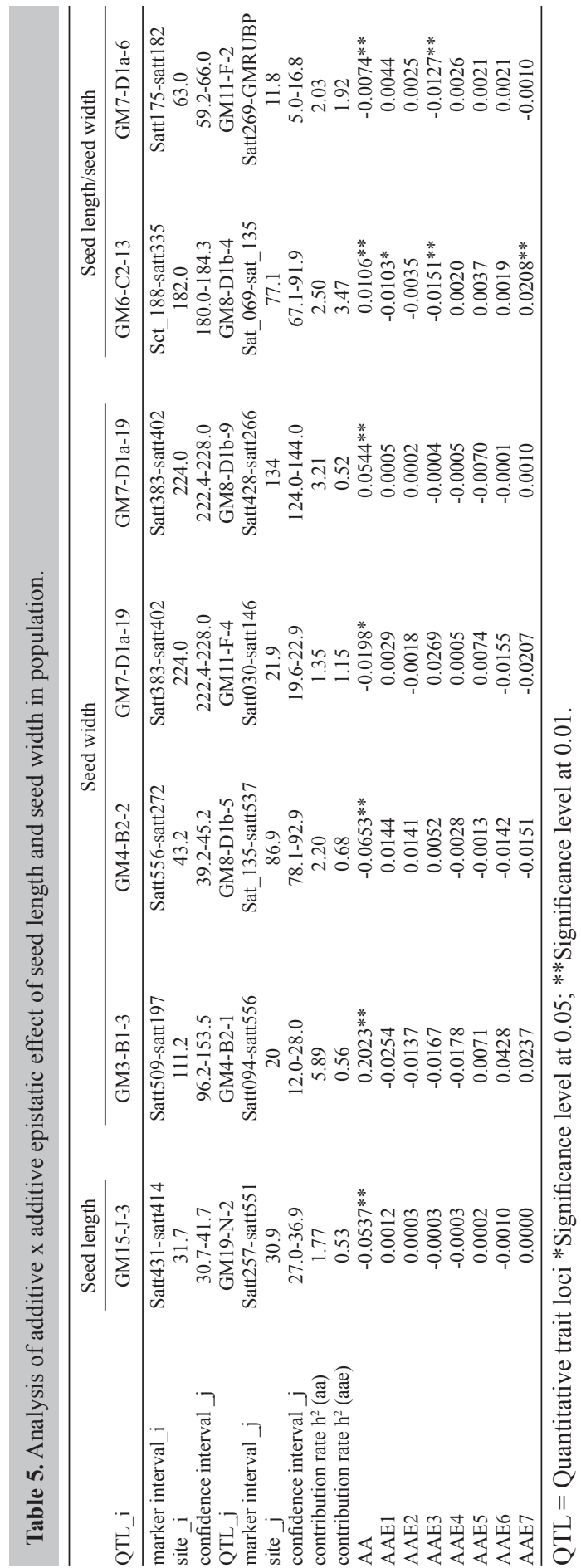


Four pairs of seed width QTLs with additive $\mathrm{x}$ additive epistatic interaction effects were identified. Two pairs occurred on the same QTL (GM7-D1a-19) between 2 other QTL sites, namely, GM8-D1b-9 and GM11-F-4. The additive effects were 0.0198 and 0.0544, respectively. Another 2 pairs of QTLs (GM3-B1-3 to GM4-B2-1 and GM4-B2-2 to GM8D1b-5) had additive effects on the paternal parent. The recombinant types showed greater effects than the parental types. The additive $\mathrm{x}$ additive contribution rates ranged from 1.35 to $5.89 \%$, the additive $\mathrm{x}$ additive environmental contribution rates ranged from 0.52 to $1.15 \%$, and the additive $\mathrm{x}$ additive total contribution rate $(12.65 \%)$ was significantly greater than that of the additive $\mathrm{x}$ additive environment contribution rate (2.91\%).

Two pairs of seed length/seed width QTLs with additive $\mathrm{x}$ additive epistatic effects occurred between the non-linkage interaction loci. The additive effects were 0.0106 and 0.0074 , and they were significant at the 0.01 level. One pair of QTLs with additive effects was from the female parent, and the effects of the parent types were greater than those of the recombinant types. Another pair of additive effects was from the male parent, and the effects of the recombinant types were greater than those of the parental types. The contribution rates of additive $\mathrm{x}$ additive effects ranged from 2.03 to $2.50 \%$. The environmental contribution rates of the additive $\mathrm{x}$ additive effects ranged from 1.92 to $3.47 \%$. The additive $\mathrm{x}$ additive environmental contribution rates of GM6-C2-13 and GM8-D1b-4 were greater than those of the additive $\mathrm{x}$ additive contribution rates. The additive $\mathrm{x}$ additive environmental contribution rate $(5.39 \%)$ of seed length/seed width was greater than that of the additive $\mathrm{x}$ additive contribution rate (4.53\%). The 7 different ecological conditions had little impact on seed length and seed width, and they had great influences on seed length/seed width during 2006 to 2010. The environment interaction effects on GM6-C2-13 and GM8-D1b-4 were significant at the 0.05 level in 2006 (A) and the 0.01 level in 2008 (A) and 2010 (B). The environment interaction effects on GM7D1b-6 and GM11-F-2 were significant at the 0.01 level in 2008 (A).

\section{DISCUSSION}

Seed length and seed width had larger changes in the different ecological conditions with different genetic backgrounds; however, the trends of the change in seed length/seed width were consistent. Two QTLs were identified on linkage group D1b and C2, and they interacted with other linkage groups for seed length/seed width, which was not inconsistent with the results of QTL underlying seed length and seed width, respectively. Further studies were needed for traits and QTL analysis. However, there were several QTLs that were related to pod wall thickness and seed nitrogen accumulation. These would add confidence to the locus underlying seed length/seed width (Panthee et al., 2005; Guo et al., 2011).

The findings of this study demonstrate that certain QTL pairs display strong epistatic effects. To our knowledge, epistatic QTLs underlying seed width, seed length, and seed length/ seed width of soybean have not been reported. In this study, 7 pairs of epistatic loci for seed length, seed width, and seed length/seed width were found; these loci occurred in the 8 linkage groups. They did not cover entire linkage groups in soybean. The additive effect contribution rates of the seed length and seed width were greater than those of additive environmental effects. The additive effect values were significant or very significant, and additive effects were significant. This result was similar that of a previous study, which reported that QTLs with significant additive and epistatic effects existed (Li et al., 2008). 
Genes controlling yield traits depended on the specific environment. Yield traits and environment interaction were important factors that affected soybean yield. Therefore, QTLs that were identified in different environments were quite different (Paterson et al., 1991; Li et al., 2003). In this study, we analyzed the seed length and seed width of the groups in 7 different environmental conditions over the span of 5 years. The QE interaction had not been identified in each of the years. For seed length/seed width, the QE interactions were identified in the different environmental conditions. The additive $\mathrm{x}$ additive environmental contribution rates of GM6-C2-13 and GM8-D1b-4 were greater than those of the additive $\mathrm{x}$ additive contribution rates. The additive $\mathrm{x}$ additive total environmental contribution rate $(5.39 \%)$ of seed length/ seed width was greater than that of the additive $\mathrm{x}$ additive total contribution rate $(4.53 \%)$ in soybean. The 7 different ecological conditions had less impact on seed length and seed width, then the ecological conditions had a great effect on seed length/seed width during 2006-2010. GM6-C2-13 and GM8-D1b-4 and the environment interaction effect reached a significant level in 2006 (A), and they reached a very significant level in 2008 (A) and 2010 (B). GM7D1b-6, GM11-F-2, and the environment interaction effect reached a very significant level in 2008 (A). These results showed that 2 QTLs were greatly influenced by the environment and were not suitable for use in molecular-assisted breeding.

\section{ACKNOWLEDGMENTS}

Research supported by the New-Century Training Programme Foundation for the Talents of Heilongjiang Province Education Ministry (\#1252-NCET-004), New Century Excellent Talents in University of Ministry of Education (\#NECT-1207-01), Nature Science Foundation Key Project of Heilongjiang Province (\#ZD201213), Public Agricultural Research Special Funds Projects (\#200903003), National Scientific and Technical Supporting Programs of China (\#2011BAD35B06-1), and China Agriculture Research System (\#CARS-04-02A). "863” project (\#2012AA101106, \#2013AA102602). Postdoctoral Science Foundation of Heilongjiang Province (\#LBH-Z12035), Postdoctoral Science Foundation of China (\#2012M520030).

\section{REFERENCES}

Guo GY, Sun R, Hou M, Guo YX, et al. (2011). Quantitative trait locus (QTL) analysis of pod related traits in different environments in soybean. Afri. J. Biotech. 10: 11848-11854.

Heang D and Sassa H (2012). Antagonistic actions of HLH/bHLH proteins are involved in grain length and weight in rice. PLoS One 7: e31325.

Ishimaru K, Hirotsu N, Madoka Y, Murakami N, et al. (2013). Loss of function of the IAA-glucose hydrolase gene TGW6 enhances rice grain weight and increases yield. Nat. Genet. 45: 707-711.

Jin J, Liu XB, Wang GH, Mi L, et al. (2010). Agronomic and physiological contributions to the yield improvement of soybean cultivars released from 1950 to 2006 in Northeast China. Field Crops Res. 115: 116-123.

Keim P, Diers BW, Olson TC and Shoemaker RC (1990). RFLP mapping in soybean: association between marker loci and variation in quantitative traits. Genetics 126: 735-742.

Kitagawa K, Kurinami S, Oki K, Abe Y, et al. (2010). A novel kinesin 13 protein regulating rice seed length. Plant Cell Physiol. 51: 1315-1329.

Li CD, Jiang HW, Zhang WB, Qiu PC, et al. (2008). QTL analysis of related trait of pod and seed in soybean. Mol. Plant Breed. 6: 1091-1100.

Li ZK, Yu SB, Lafitte HR, Huang N, et al. (2003). QTL x environment interactions in rice. I. heading date and plant height. Theor. Appl. Genet. 108: 141-153.

Liang HZ, Wang SF, Yu YL, Wang TF, et al. (2008). QTL mapping of 6 types seed shape trait in soybean. Henan Agri. Sci. 9: 45-51. 
Lu C, Shen L, He P, Chen Y, et al. (1997). Comparative mapping of QTLs for agronomic traits of rice across environments by using a doubled-haploid population. Theor. Appl. Genet. 94: 145-150.

McKenzie KS and Rutger JN (1983). Genetic analysis of amylose content, alkali spreading score, and grain dimensions in rice. Crop Sci. 23: 306-313.

Niu Y, Xu Y, Liu XF, Yang SX, et al. (2013). Association mapping for seed size and shape traits in soybean cultivars. Mol. Breed. 31: 785-794.

Panthee DR, Pantalone VR, West DR, Saxton AM, et al. (2005). Quantitative trait loci for seed protein and oil concentration, and seed size in soybean. Crop Sci. 45: 2015-2022.

Paterson AH, Damon S, Hewitt JD, Zamir D, et al. (1991). Mendelian factors underlying quantitative traits in tomato: comparison across species, generations, and environments. Genetics 127: 181-197.

Salas P, Oyarzo-Llaipen JC, Wang D, Chase K, et al. (2006). Genetic mapping of seed shape in three populations of recombinant inbred lines of soybean (Glycine max L. Merr.). Theor. Appl. Genet. 113: 1459-1466.

Song XJ, Huang W, Shi M, Zhu MZ, et al. (2007). A QTL for rice grain width and weight encodes a previously unknown RING-type E3 ubiquitin ligase. Nat. Genet. 39: 623-630.

Sun YN, Pan JB, Shi XL, Du XY, et al. (2012). Multi-environment mapping and meta-analysis of 100-seed weight in soybean. Mol. Biol. Rep. 39: 9435-9443.

Tasma IM, Lorenzen LL, Green DE and Shoemaker RC (2001). Mapping genetic loci for flowering times, maturity, and photoperiod insensitiv ity in soy bean. Mol. Breed. 8: 25-35.

Wang YJ, Huang ZJ, Deng DX, Ding HD, et al. (2013). Meta-analysis combined with syntenic metaQTL mining dissects candidate loci for maize yield. Mol. Breed. 31: 601-614.

Xu Y, Li HN, Li GJ, Wang X, et al. (2011). Mapping quantitative trait loci for seed size traits in soybean (Glycine max L. Merr.). Theor. Appl. Genet. 122: 581-594.

Yesudas CR, Bashir R, Geisler MB and Lightfoot DA (2013). Identification of germplasm with stacked QTL underlying seed traits in an inbred soybean population from cultivars Essex and Forrest. Mol. Breed. 31: 693-703.

Zhang D, Cheng H, Wang H, Zhang H, et al. (2010). Identification of genomic regions determining flower and pod numbers development in soybean (Glycine max L.). J. Genet. Genomics 37: 545-556. 